\title{
Differenz
}

Revista internacional de estudios heideggerianos y sus derivas contemporáneas

AÑO 4, NÚMERO 3: JULIO DE 2017. e-ISSN 2386-4877 - DOI: 10.12795/Differenz.2017.i03.01

[pp. 11-32]

Recibido: 04/08/2015

Aceptado: 03/09/2016

\section{La noción de comunidad en Heidegger y su recepción en la filosofía francesa}

\section{Heidegger's notion of Community and its reception in French philosophy}

\author{
Leticia Basso Monteverde \\ Universidad de Buenos Aires
}

\section{Resumen:}

El trabajo aborda la noción de comunidad en Heidegger en sus escritos y discursos del período del Rectorado en Friburgo (1933/34) y la compara con la perspectiva francesa (Bataille, Blanchot, Derrida, Nancy) en torno al debate contemporáneo sobre la comunidad. A propósito se analizan en detalle las nociones heideggerianas que estos pensadores trabajan, para distinguir qué aspectos de éstas retoman y cuáles rechazan. Con esto, el trabajo sostiene que esta comparación permite elaborar una reflexión sobre la tensión inherente a la noción de comunidad y, de este modo, descubrir por qué esta tensión es parte de su naturaleza.

Palabras Clave: Heidegger; comunidad; origen; identidad; interpretación francesa 


\section{Abstract:}

This paper discusses Heidegger's notion of Community in his work and lectures of Freiburg's period (1933/1934) and compares it with the French perspective (Bataille, Blanchot, Derrida, Nancy) about the contemporary debate over community. This article presents the Heideggerian notions that these thinkers work to distinguish which aspects of them they take and which ones reject. Finally, this article argues that this comparison allows thinking about the inherent Tension of the notion of Community and find out why this Tension its part of his nature.

Keywords: Heidegger; community; origin; identity; French interpretation

¿Cuál es el ser de la comunidad, qué ontología da cuenta de eso que indica una palabra conocida -común- pero cuyo concepto se ha vuelto muy incierto?

Jean-Luc Nancy, La comunidad enfrentada.

\section{Introducción}

El siguiente trabajo analiza la noción de comunidad (Gemeinschaft) en Heidegger, formada en sus escritos y discursos de la década del '30. Para el filósofo la comunidad se realiza mediante los ideales de pertenencia e identidad de un pueblo, que en busca de su destino asume y reconfigura su tradición. Así pues, por medio del reconocimiento de su legado, el temple de ánimo que lo caracteriza y la decisión que todo esto implica, se logra la revitalización del origen de la comunidad.

Entonces, este trabajo postula que para comprender la noción de comunidad en Heidegger se requiere reflexionar acerca de los factores ontológicos, éticos y políticos que la determinan. Para esto, es de gran ayuda retomar la recepción francesa de algunas de las nociones heideggerianas y su interpretación respecto al debate en torno a la comunidad. Según las lecturas de pensadores como Bataille, Blanchot, Derrida y Nancy, estas nociones deben examinarse y deconstruirse en vistas a dilucidar una concepción de comunidad que no ejerza la violencia inherente a la apropiación y la autenticidad de sí mismo, ya que de este modo se omiten la otredad y la expropiación que los pensadores reivindican.

La línea francesa plantea un análisis ontológico de los elementos que articulan el fenómeno de comunidad en el mundo contemporáneo. Para esto, sus pensadores representativos rastrean el origen simbólico del concepto y develan -a través de una 
crítica al paradigma moderno- los presupuestos que delimitan la concepción y moldean la actitud de la época. De este modo, descubren la necesidad de meditar acerca de una idea de comunidad que se despegue de la carga significativa asociada a la visión catalogada como "filosofía de la subjetividad" y su organización totalitaria, inmanente y partidaria de una actitud productiva. Para los franceses la comunidad es desobrada; en ella no hay una identidad que mancomune a todos en un lugar. Lo común del "ser-con" (Mitsein) es el estar afuera expropiado de sí y el "ser-para-la-muerte" remite a la finitud del hombre y la falta de un fundamento debido a su cercanía a lo abismal e indeterminado.

Si queremos adentrarnos en la obra del Heidegger de inicios de la década del ' 30 y abordar su noción de comunidad, podemos comenzar con el análisis de los textos y discursos que describen su interés y preocupación por la misión de la comunidad, tales como Das Rektorat, Die deutsche Universität y Die Selbstbehauptung der deutschen Universität. Sin embargo, primero debemos analizar algunas nociones que la línea francesa critica y, a la vez, descubrir otras cuestiones que deben discutirse para comprender el problema de la comunidad a luz de su debate en la actualidad. Por lo tanto, a lo largo del trabajo: expondremos la interpretación heideggeriana de la comunidad y señalaremos los puntos más relevantes para comprenderla; contextualizaremos su pensamiento en el período en cuestión e indicaremos sus influencias y aquello a lo que Heidegger se opone; y retomaremos algunas lecturas francesas para dialogar con ellas y para entender su perspectiva del tema.

\section{El sentido del origen de la comunidad: dos perspectivas}

Martin Heidegger se caracteriza por un pensar radical y renovador que propone una revisión de la tradición occidental, fundada en el replanteo de la pregunta por el sentido del ser. Desde sus cursos tempranos hasta Sein und Zeit e -incluso- más allá de su obra capital, el pensador instaura la necesidad de una recuperación del origen. Del mismo modo, la cuestión del origen es un tema central en los pensadores de la comunidad, ya que para ellos el origen negativo y disolutivo de la comunidad es el factor principal para comprender el sentido de expropiación y el abismo que nos acomuna. En principio, podemos afirmar que tanto para Heidegger como para estos pensadores la cuestión del origen sustenta el sentido de la comunidad. Por tal motivo, ambos análisis proponen un estudio detallado del origen y una vuelta al mismo para develar cada forma posible de comunidad. No obstante, si nos concentramos en el período en el cual Heidegger reflexiona sobre la comunidad, veremos que aquello que él entiende por origen dista de lo que los franceses formulan. 
La cuestión de la comunidad en el pensamiento de Heidegger se inicia con una propuesta que acentúa la tradición a través de un proyecto vinculado a la transformación del pueblo. Este proyecto se realiza en vistas a la configuración del destino por una serie de pilares que lo refuerzan: la patria, la tierra, el origen alemán, el compromiso social, la militancia estudiantil y el trabajo por el saber. Para abordar la idea de comunidad en Heidegger trabajaremos en este escrito: las influencias del contexto histórico y la relación que el filósofo mantiene con la política, a través de la distinción de su accionar público y su pensar. Para esto nos introduciremos en los discursos del autor pertenecientes a su período del Rectorado en Friburgo, pues en ellos se encuentran -en su máxima expresiónlas intrigas, los reclamos y las expectativas respecto al camino recorrido por el partido Nacionalsocialista y el tercer Reich. La reconstrucción de estos tópicos se llevará a cabo por medio de un eje vertebrador que destaca el énfasis que pone Heidegger en la idea de una conducción espiritual (geistige Führung) del pueblo para una identificación y apropiación de su destino. De este modo, la propuesta de Heidegger busca encaminar una transformación que parta desde el origen del pensar hacia una autoafirmación de la universidad alemana y su esencia, con el objetivo de una futura participación activa de la comunidad en el estado.

Por el contrario, la línea de pensamiento francesa sostiene que este tipo de comprensión -a partir de la cual se tiene una mirada teleológica que apunta al sentido y la realización del destino prefigurado- debe entenderse como la contracara del fenómeno originario de comunidad. Esto se debe a que los rasgos esenciales de la noción heideggeriana se encuadran dentro de -lo que el filósofo italiano Roberto Esposito llama- un "paradigma inmunitario". Es decir, que tal idea de comunidad permanece dentro de los parámetros de la modernidad y desarrolla una teoría que, lejos de adherir al sentido original de la noción, refuerza los mecanismos de defensa que la protegen de su naturaleza negativa. En efecto, Heidegger afirma que lo positivo del origen o de la comunidad ejemplar -la griega- reside en la postura auténtica frente a la situación que nos interpela, y tal postura es la de la decisión y el repliegue sobre sí mismo. Como sabemos, los franceses plantean un origen y sentido de la comunidad que se proyecta fuera de sí, por ejemplo, "el éxtasis" en la experiencia interior y "la comunicación de la falta" en Bataille son elementos fundamentales que descubren el abismo primigenio que tenemos en común, que no es una propiedad o cualidad que compartamos.

Una vez esbozado en sus aspectos generales el límite que separa estas dos interpretaciones de comunidad, queremos señalar que -más allá de las diferencias o las similitudes que en el trabajo mencionemos entre ambas lecturas- lo relevante consiste en comprender cómo estas son dos caras de un fenómeno mayor. Dicho fenómeno expresa el 
vínculo indisoluble entre la comunidad de expropiación y apropiación. En otras palabras, la doble dimensión que la lógica de Esposito en la tensión de comunidad e inmunidad plantea.

A continuación, haremos algunas precisiones acerca de ciertas nociones de Heidegger que forman parte del problema de la comunidad, para exponer y discutir su sentido en la interpretación francesa respecto al marco de su debate actual.

\section{Revisión de algunas nociones de Heidegger y análisis de la propuesta francesa}

Hay ciertos parecidos entre la visión francesa -de influencia nietzscheana- y la obra de Heidegger posterior al viraje (Kehre) de su pensar. En las exposiciones de la línea francesa encontramos ciertas notas descriptivas que nos acercan tanto al estilo poético y asistemático de Heidegger como a las problemáticas y tensiones propias de la donación y lo inaparente en el campo de la fenomenología. Cuestiones como la diferencia, la falta de fundamento, lo abismal, el entre y el lenguaje del ser, entre otras, transitan por un camino similar al de los franceses.

Si nos focalizamos en el Heidegger de los '20 o en los discursos del período del Rectorado -en los cuales elabora por primera vez su noción de comunidad- veremos que las formas de abordar la problemática en el filósofo alemán no tienen todavía el tono que con la Kehre se asemeja al de los pensadores franceses. Esto se debe a que todavía Heidegger no había profundizado en su reconocimiento de la indigencia del pensar, la necesidad del tránsito y el programa de la historia del ser (Geschichte des Seyns).

En este escrito nos concentraremos en el momento en que justamente se inicia la inflexión del tratamiento de todo el complejo temático (Sachverhalt), puesto a que su idea de comunidad se gesta particularmente en la instancia anterior a la Kehre. Para muchos de sus intérpretes, Heidegger se encontraba en este período inmerso aún en una "metafísica de la subjetividad", ya que con Sein und Zeit no logra acceder a un lenguaje que le permita reformular la pregunta por el ser más allá de la constitución trascendental del Dasein. Del mismo modo, su tematización del problema de la comunidad y el proyecto que presenta para revitalizar el origen están determinados por el pensamiento moderno.

En este apartado del trabajo intentaremos mostrar algunos de los rasgos principales de la concepción francesa y destacar su interpretación de aquellas nociones heideggerianas que retoma o rechaza, con el fin de compararla con la idea de comunidad del pensador alemán. En el ámbito filosófico contemporáneo los pensadores franceses proponen una reflexión ontológica sobre la comunidad. Esta línea quiere pensar la noción fuera de toda 
idea de producción porque instituye un sentido que delimita a la comunidad y la define de forma tal que oscurece su naturaleza. En efecto, el problema de la comunidad surge justamente cuando se intenta acceder a ella por medio del obrar. Para los franceses la idea de producción condiciona a la comunidad y niega su origen, ya que sólo negándola puede surgir algo constituido de ella. En este sentido, pretende plantearse una forma nueva de abordar esta cuestión, lejos de los rasgos modernos que la determinan.

Para los franceses "...la 'comunidad' nos está dada, es decir un 'nosotros' nos está dado antes de que podamos articular un 'nosotros', y todavía menos justificarlo." ${ }^{1}$ Los pensadores franceses intentan retrotraerse a la idea pre-ontológica de que la comunidad es previa a toda formación de orden social. Con esta idea los autores indican que existe una modalidad previa a toda producción de mundo y construcción identitaria, esta modalidad es el "ser-con". El "ser-con" (Mitsein) es lo que somos a partir del otro. Esta concepción señala que el hombre ya es junto a otros, e incluso es gracias a otros. La idea plantea una nueva forma de comprender al sujeto, distinta de aquella que en la modernidad se estableció a partir de la idea de una conciencia de sí, de cierta propiedad e identidad constitutiva del yo. Pues bien, para los pensadores de la comunidad no existe mismidad ni reconocimiento alguno que nos brinde una forma acabada de nuestro ser y nos permita acceder a nuestra esencia. Al respecto, Blanchot escribe -siguiendo a Batailleen La comunidad inconfesable que:

En la base de cada ser, existe un principio de insuficiencia (principio de incompletud). Es un principio lo que manda y ordena la posibilidad de ser. De ahí resulta que la carencia por principio no va a la par de una necesidad de completud. ${ }^{2}$

Con esto, Blanchot señala que tal conciencia de la insuficiencia y desintegración necesita del otro o de algo distinto para realizarse. El ser busca no ser reconocido, sino impugnado pues la privación lo hace consciente de la imposibilidad de ser él mismo. ${ }^{3}$

Por consiguiente, la comunidad es esta forma de compartir el ser carencial que somos. Al respecto, Nancy dice en La comunidad enfrentada:

Hay que sostener (...) la severidad de la relación con lo extraño cuya extrañeza es condición estricta de existencia y de presencia. $Y$ hay que sostener eso que, delante de nosotros, nos expone al sombrío resplandor

1 NANCY, La comunidad enfrentada, Buenos Aires: La cebra, 2007, p. 34.

2 BLANCHOT, La comunidad inconfesable, Madrid: Arena Libros, 1999, p. 21.

3 Cfr. BLANCHOT, La comunidad inconfesable cit., pp. 21-22. 
de nuestro propio devenir y de nuestra propia desgarradura (...) se trata de pensar un mundo por sí mismo fracturado... ${ }^{4}$

De esta manera, la comunidad es la triple forma de: lo otro alejado, lo mismo retirado y la historia de lo no ocurrido, estas tres formas de ser son el origen de la comunidad. Aunque esta manera de existir o co-existir es difícil de soportar, el hombre tiende a huir del estado desgarrado y frente a la falta de completud la filosofía moderna presenta al sujeto como un individuo que rompe con la comunidad, porque corta el vínculo con el otro y de esta manera evita toda responsabilidad que exceda a su ser y se libera de toda carga. De aquí surge el derecho, que lo protege de su naturaleza, lo define como un propietario y lo inmuniza de todo deber. Sobre esta potencia de negación, Nancy señala en La comunidad desobrada que:

el individuo no es más que el residuo de la experiencia de la disolución de la comunidad. Por su naturaleza -como su nombre lo indica, es el átomo, lo indivisible-, el individuo revela ser el resultado abstracto de una descomposición. ${ }^{5}$

Entonces, frente a la idea de individuo los franceses proponen la idea del "ser-con" que Heidegger describe en la década del '20, principalmente en Sein und Zeit.

Con todo, el "ser-con" heideggeriano del que los franceses toman y generan su visión, apunta al hecho de que somos con el otro en el modo del cuidado y la solicitud (Fürsorge). ${ }^{6}$ Esto significa que el Mitsein pertenece a la estructura modal a priori, condición de posibilidad de todo aquello que puede darse fácticamente en la existencia. Con esto queremos resaltar los caracteres de relación y ejecución que tienen cada uno de los existenciales, que el pensamiento francés no va a retomar. Por lo tanto, esta línea de pensamiento reformula la idea del "ser-con" dejando de lado las notas de reciprocidad o intersubjetividad que pudieran estar presentes en el pensamiento de Heidegger. Esto se debe a que ambas apuntan a una relación que se establece entre sujetos que implica: por un lado, una instancia previa a la relación -ya que ambos son antes del vínculo- y, por otro lado, un ida y vuelta en la lógica de la donación -porque los franceses e italianos plantean la unilateralidad del don, es decir, la idea de que el don es en la dación sin la espera de algo a cambio. Por estos dos motivos estos pensadores proponen una nueva forma del

\footnotetext{
4 NANCY, La comunidad enfrentada cit., p. 15.

5 NANCY, La comunidad desobrada, Madrid: Arena Libros, 2011, p. 17.

6 "La solicitud de otro Dasein es la Fürsorge. La Fürsorge en el sentido de institución social fáctica, se funda en la estructura del ser del Dasein que es el coestar. Su urgencia fáctica deriva de la deficiencia de la solicitud, de la falta de atención del uno para el otro." HEIDEGGER, Sein und Zeit, Tübingen, Max Niemeyer Verlag, 1960, p. 121.
} 
"ser-con" que refiere exclusivamente a la importancia de aclarar que en la comunidad ya somos con el otro en la expropiación y lejos de todo condicionamiento del vínculo. Para Nancy el "con" es seco y neutro: ni comunión ni atomización, es compartir apenas un lugar: un estar juntos sin ensamble. ${ }^{7}$ No obstante, no queremos afirmar que el "ser-con" heideggeriano presenta una relación intersubjetiva entre sujetos previamente dados, sino que la idea de la reciprocidad o el cuidado contienen vestigios de la tradición moderna $y$, por ende, la perspectiva francesa necesita liberar la noción pre-ontológica de estos supuestos.

Por otro lado, tanto Bataille como Nancy analizan la idea del "estar expuesto". Creemos que esta idea no puede relacionarse en su totalidad con el ex-sistere heideggeriano porque este modo de la apertura se concreta con la póiesis. La apertura es condición de posibilidad para que el Dasein configure su mundo. La concepción de mundo que Heidegger retoma de pensadores como Hamann, Herder y von Humboldt plantea la idea del lenguaje como apertura de mundo y este paradigma refuerza la producción de sentido. Entonces, toda producción indica una obra que busca la pertenencia y la identidad con su productor. Por este motivo, el ex-sistere heideggeriano que refiere a la idea de la inmanencia de hombre y mundo en la vivencia fue planteada en contra de la comprensión gnoseológica moderna, pero para atender a todo vínculo remisional y significativo del Dasein. Por consiguiente, tanto en el "ser-con" como en el "estar-expuesto" se encuentran elementos que les sirven a los pensadores de la comunidad e implicancias que deben descartar, si desean formar una ontología distinta.

Esta advertencia se plantea más que nada para tener en cuenta que el marco teórico en el que se insertan las nociones heideggerianas apunta a metas y contenidos distintos de aquello que el pensamiento francés presenta. Sin embargo, los conceptos del filósofo alemán -entendidos más allá del influjo y su contexto- refieren a fenómenos o formas de manifestación que a la perspectiva francesa le interesan para mostrar el sentido de la comunidad y la naturaleza de los hombres en ella. Por ejemplo, la idea del éxtasis le permite a los franceses marcar la imposibilidad de la absolutez del individuo, o sea, desligar al sujeto de la contención que brinda la inmanencia. Nancy dice que: “...la comunidad no es un proyecto fusional, ni de manera general un proyecto productor u operatorio." 8

Es de suma importancia indicar que los autores franceses se remiten a una interpretación in-comunitarista. Al respecto Mónica Cragnolini explica que esta idea apunta a

7 Véase NANCY, La comunidad enfrentada cit., p. 29.

8 NANCY, La comunidad desobrada cit., p. 35. 
nexos de no aproximación y no pertenencia, (...) este pensamiento de la comunidad no hace referencia a un modo de relación con el otro (del que sería derivable una ética normativa y una política de lo posible). ${ }^{9}$

Toda forma de organización social, toda institución y gestión en la comunidad, tienen en cuenta las ideas de pertenencia, identidad y apropiación que Heidegger apoya en los discursos del Rectorado y que otras lecturas filosóficas mantienen. Ahora bien, repensar la comunidad desde los franceses nos lleva al deshacimiento y a lo impolítico, es decir, a la disolución de toda posibilidad de proyectar o accionar. La comunidad plantea una nueva reflexión donde ontología y política se cruzan en una forma que más que configurar busca desentrañar el origen y detenerse en lo que tenemos en común para atender a las necesidades del otro sin traducirlas a las nuestras. Sin duda alguna, es el éxtasis el que permite hacer de cada uno el lugar del otro.

La forma del éxtasis se relaciona con otra noción heideggeriana: el "ser-para-lamuerte". Cragnolini señala que es fundamental la problemática de la muerte porque permite desbaratar el carácter fundacional del sujeto y la comunidad. ${ }^{10} \mathrm{El}$ "ser-parala-muerte" expone la nada que somos, la falta de un origen determinado. A propósito, consideramos que esta lectura se contrapone a la idea de Heidegger en algunos puntos que tienen que ver, como en las otras nociones, con el plexo significativo que se abre en cada modo de la existencia. El "ser-para-la-muerte" es para Heidegger la posibilidad más propia porque es el existencial que le abre al Dasein el horizonte de posibilidades a concretarse y la culminación de todo ello en la instancia de la muerte, que es la muerte propia y no la del otro -como entiende la filosofía francesa. Cragnolini señala que la posibilidad de la muerte lleva al Dasein al "retorno a sí" a través del llamado (Anruf). ${ }^{11} \mathrm{En}$ este sentido, el "ser-para-la-muerte" no tiene en cuenta el "ser-con" que somos, sino que refiere directa y únicamente al sí mismo. Sin embargo, incluso en el sí mismo se puede generar -frente a la posibilidad de la muerte- una recaída en el mundo del "uno" (das Man), la instancia impersonal o anónima en la que los Dasein co-existen negando aquel componente originario que lo define. Así pues, sostenemos que esta forma de entender el "ser-para-la-muerte" abriga una connotación inmunitaria que refleja a partir de un estado de ánimo, con total claridad, la dialéctica tensional que el fenómeno de la comunidad

9 CRAGNOLINI, M. "Extrañas comunidades. Para una metafísica del exilio" en CRAGNOLINI, M. (comp.), Extrañas comunidades. La impronta nietzscheana en el debate contemporáneo, Buenos Aires: La cebra, 2009, p. 52.

10 Ibidem, p. 56.

11 Cfr. CRAGnolinI, M. "Temblores del pesar: Nietzsche, Blanchot, Derrida" en Pensamientos de los confines, $\mathrm{N}^{\circ} 12$, junio, 2002, p. 115. 
presenta. Por lo tanto, esta exposición que revela la esencia del hombre, su finitud, muestra cómo la condición extática de la experiencia humana nos lleva a negarnos para protegernos del origen indeterminado que tenemos. Entonces, frente a la interpretación del "ser-para-la-muerte" como retorno al sí mismo y revisión de sus posibilidades vitales, creemos que esta otra forma de ser del hombre frente a la muerte nos enfrenta a la nada que somos y al abismo que nos constituye. Ya Heidegger en reiteradas ocasiones y diversas obras aborda la angustia (Angst) que genera este tipo de exposición abrumadora.

Por otro lado, teniendo en cuenta las consecuencias del fenómeno de la muerte más allá del plano personal y en relación a sus efectos, Nancy indica en su escrito "Conloquium" que la reflexión en torno a la comunidad se impuso, y se volvió inevitable, por motivo del terrible fenómeno de muerte que forma parte de nuestra historia. Al respecto Nancy nos dice, “...en nombre de la comunidad, la humanidad -ante todo en Europa- puso a prueba una capacidad insospechada de autodestrucción."12 Más adelante completa, que esta obra de muerte "...es lo que ha puesto fin a toda posibilidad de basarse sobre cualquier forma de lo dado del ser común." ${ }^{13}$ De aquí se sigue indudablemente el punto de que los pensadores franceses demanden dejar atrás todo modelo comunitarista que rescate la identidad, la reunión y un objetivo en común. Sin embargo, es casi imposible desligarnos del "ser-con", nuestra naturaleza nos lleva a ser y pensar-nos indisociados. Del mismo modo, si somos en el "ser-con" es lógico que surjan intentos de distinción, puesto que Nancy explica que si no fuéramos junto a otros, no cabría hablar de un "yo". Heidegger en Sein und Zeit define el sí mismo (das Selbst) justamente a favor de la distinción uno mismo, así nos dice:

El Dasein es el ente que soy cada vez yo mismo; su ser es siempre el mío. (...) El quién queda respondido desde el "yo mismo", el "sujeto", el "sí" (das "Selbst") (...) El quién es lo que a través del cambio de los comportamientos y vivencias se mantiene idéntico y de esta manera se relaciona con esta multiplicidad. (...) Es el mismo en medio de la multiplicidad de las diferencias, el carácter de la mismidad ${ }^{14 .}$

En otro pasaje de Sein und Zeit Heidegger plantea, quizás, algo más cercano a la idea de los franceses, a saber:

12 NANCY, "Conloquium" en ESPOSITO, R., Communitas. Origen y destino de la comunidad, Buenos Aires: Amorrortu, 2003, p. 10.

13 Ibidem, p. 11.

14 HEIDEGGER, Sein und Zeit cit., p. 114. 
"los otros" no quiere decir todos los demás fuera de mí, y en contraste con el yo; los otros son, más bien, aquellos de quienes uno mismo generalmente no se distingue, entre los cuales también se está. Este existir también con ellos no tiene el carácter ontológico de un "co"-estar-ahí dentro del mundo.

El "con" tiene el modo de ser del Dasein; él también se refiere a la igualdad del ser. ${ }^{15}$

En este fragmento observamos cierta cercanía a la idea de que somos algo indeterminado, es decir, de que somos pre-ontológicamente en el "con". De este modo Nancy en "Conloquium" trabaja las nociones heideggerianas y llega a la conclusión de que el "ser-con" es en lo abierto, porque en el "ser-con" estamos expuestos a otros en la proximidad o lejanía, donde el "con" es el topos del sentido. El sentido en el "ser-con" está en la exposición que somos. Para Nancy debe plantearse un vínculo sin comunión, él encuentra en la comparecencia, una forma más originaria de expresar "el entre" en el que ya estamos.

En adelante, con ayuda de la revisión de las nociones heideggerianas y a la luz de la interpretación de la línea francesa que estudia la comunidad, nos introduciremos en los discursos de Heidegger del período del Rectorado para analizar su reflexión acerca de la comunidad y el programa que propone para revitalizar su origen y afirmar su esencia.

\section{El programa de Heidegger en el período del Rectorado y su noción de comunidad}

Con el Rectorado de la Universidad de Friburgo en 1933, Heidegger inicia una serie de discursos referentes a su posición, su función y la misión a emprender en la casa de altos estudios. En el discurso pronunciado por motivo de la asunción del cargo, Heidegger decide inaugurar su actividad retomando la pregunta central que planteó en Was ist Metaphysik? Pregunta que problematizaba nuestra existencia haciendo, en este caso, un particular hincapié en la existencia del sector intelectual universitario y su pasión por la ciencia. Vale destacar que el pensamiento de Heidegger sobre la comunidad nace por la preocupación ante la situación que experimentaba en el sector universitario y en Alemania en general. En este contexto, el filósofo muestra que la ciencia se encontraba ramificada y dispersa en sus estudios disciplinarios, siendo sólo unificada por la organización de la técnica. A su vez, también destaca que la raíz esencial de las ciencias, su fundamento, se había perdido. Por este motivo, Heidegger propone generar una ciencia fundamental que integre los conocimientos teóricos en un saber que funde las bases para estas ciencias.

15 Ibidem, p. 118. 
Frente a la propaganda del partido en vigencia, Heidegger propone -supuestamenteotra forma de afirmar la esencia de la comunidad. El profesor estaba preocupado por el sector intelectual y temía la pérdida de aquellos valores y costumbres que arraigaban en su provincia. Lamentablemente, con la publicación de los Schwarze Hefte ${ }^{16}$ terminamos de confirmar la adhesión de Heidegger a los ideales del Nacionalsocialismo y la mentalidad antisemita que en el plano intelectual -según el editor de los textos Peter Trawny- también teñía la interpretación heideggeriana y el propósito de configuración universitaria que pretendía. Debajo veremos claramente los matices que le imprime a su discurso y la tonalidad afectiva que le impone a su tarea. Respecto a estos asuntos uno no puede omitir efectuar un juicio negativo y recalcar la falta de responsabilidad del pensador, más que nada por la inexistente revisión y crítica explicita de su postura e ideas luego del terrible Holocausto.

En Das Rektorat Heidegger expone de forma detallada su experiencia personal en el cargo universitario. Las dificultades que se presentaron frente a sus intentos de llevar a cabo su función e ideas, y la defensa de su visión e intereses en contraposición a los del partido en vigencia. Ante todo, Heidegger dice que aceptó el puesto por tres razones: 1) para renovar y unir interiormente al pueblo en busca de su destino, haciendo participe a la universidad de la misión del pueblo, 2) para conducir como "guía espiritual" a las fuerzas capaces, con independencia de su pertenencia al partido y su doctrina, al proceso de reflexión y renovación, fortaleciendo y asegurando su influjo y 3) para hacer frente a la penetración de personas inadecuadas y a la amenazadora hegemonía del aparato y de la doctrina del partido. ${ }^{17}$

Heidegger destaca que nunca fue llamado a ningún tipo de deliberación política por el partido y que rechazaba la idea de una ciencia política propagada por el Nacionalsocialismo como grosera simplificación de la concepción de verdad. En este sentido quiso separar su figura del estado, reclamando la necesidad de reconducir desde el saber a los sectores intelectuales. Concretamente, bajo la figura del "guía espiritual" buscaba restaurar la tradición griega y retomar la esencia de la verdad a favor de una ciencia (Wissenschaft) con saber (Wissen) y de un pensamiento libre de las construcciones políticas actuales. Debido a que pese a apoyar la base del Nacionalsocialismo como pertenencia propia y auténtica del pueblo desde la identidad, el filósofo disiente con éste acerca de los caminos

16 Publicado en tres tomos de la GA de Heidegger 94, 95 y 96 que comprenden las Überlegungen II-VI (Schwarze Hefte 1931-1938); Überlegungen VII-XI (Schwarze Hefte 1938-1939) y Überlegungen XII-XV (Schwarze Hefte 1939-1941) en Franckfurt am Main: Vittorio Klostermann, 2014.

17 HEIDEGGER, "Das Rektorat" en Reden und andere Zeugnisse. Eines Lenbensweges, GA 16, Frankfurt am Main: Vittorio Klostermann, 2000, p. 374 
que ha seguido. En este sentido, el pensamiento de Heidegger sobre la comunidad se constituye bajo los pilares de la tradición con su carga conservadora y de lo histórico por la determinación de la esencia y la experiencia en el territorio de origen.

En el discurso Die Selbstbehauptung der deutschen Universität Heidegger insiste en que el poder del espíritu ${ }^{18}$ debe guiar a los guías, o sea, que hay que conducir el destino del pueblo a partir de la misión emprendida por los intelectuales, puesto que el saber encamina a la comunidad. De esta manera, la comunidad intelectual arraigaría en la disposición fundamental. Entonces, Heidegger se pregunta si la alta escuela se encontraba realmente dentro de esta misión y duda acerca de si verdaderamente se quería arribar a esta esencia y comprender su existencia. Para conducir al sector intelectual a este temple particular, el filósofo indica que hay que llevar a cabo autoafirmación.

Ciencia, saber, destino y tradición están conectadas y fundan las bases del estado, por esto hay que retomar qué es la ciencia. Heidegger resalta la función de preguntar por la ciencia para retomar el inicio (griego) que ya está fijado en el futuro por la grandeza de su comienzo, con el fin de criticar la condición de crisis actual de la ciencia. Tal pregunta recogería las esencias diseminadas en las disciplinas y campos experimentales para conjugarlas en una sola expresión que reforzaría su máxima presencia. Para esto Heidegger propone dejar atrás al espíritu moderno y su falsa noción de libertad, pues no cree correcto el ejercicio libre desde el desarraigo de los factores que nos determinan y completan.

Por otro lado, Heidegger analiza la emancipación (Befreiung) de la modernidad y distingue su alejamiento de la idea de una comunidad. El filósofo considera que el hombre moderno se desliga de las formas originarias de la comunidad para ser un individuo. El individuo moderno es norma y fundamento, y la comunidad es reemplazada por la sociedad (Gesellschaft) que por medio de un contrato, la racionalidad y una construcción artificial regula y organiza. ${ }^{19}$ En contra de esta visión, Heidegger considera que la nueva universidad debe mantener una libertad desde la integración, y ésta se cumple mediante un saber acerca del todo, de las leyes y su querer. El autor sostiene que la visión del todo, dadora de sentido, hace falta ya que la técnica por la industrialización desgarró al pueblo en clases y partidos. A propósito, promueve un poder originario y espiritual que sane la deficiencia planteada, ligue y dé libertad al conjunto. La ley que le otorgue al pueblo el tan ansiado sentido de pertenencia a una morada, al todo.

18 Heidegger se refiere al "espíritu" como la decisión que surge del estar templado y consiente por la esencia del ser.

19 Esta distinción entre Gemeinschaft y Gesellschaft es central para los pensadores franceses porque de esta distinción nace la idea de comunidad. 
En dos breves cursos expuestos en Die deutsche Universität, Heidegger se pregunta: ¿cómo debemos comprender la esencia de la universidad? Y responde a través de la historia de dicha universidad, es decir, de su espíritu alemán. Asimismo en Die Selbstbehauptung der deutschen Universität Heidegger se pregunta si la universidad está enraizada auténticamente y en común en su esencia. En este sentido, el autor plantea la importancia de conocer el pasado para desde el presente configurar el futuro, pues se está viviendo para Heidegger un cambio que atraviesa la realidad, y su comienzo está, a sus ojos, en el Nacional-socialismo.

El término Volkstum surge para designar lo popular y comunitario en el romanticismo alemán, que creó en su momento la base universitaria que Heidegger añora. Ahora bien, luego, con la revolución Nacionalsocialista se va consolidando una nueva idea de comunidad (Gemeinschaft). A partir de esta noción, que influyó a muchos pensadores de la época y perturbó a tantos otros, Heidegger presenta la idea de una decisión espiritual que toma cuerpo en instancias radicales, que no tienen que ver con los hechos o cambios externos sino que son un profundo acontecimiento que arrasa con la visión del hombre y de su pensar, transformando al pueblo y a su voluntad.

En el frente de combate -dice Heidegger en Die deutsche Universität- se ejerce la voluntad de la comunidad en la forma del compañerismo (Kameradschaft), de la pertenencia recíproca del uno para el otro. Hay que distinguir dos ideas respecto al sentido del combate en el discurso heideggeriano: 1) la primera reposa en el sentido de lucha o conflicto al que Heidegger se refiere en Das Recktorat, que proviene de su lectura del fragmento 53 de Heráclito acerca del pólemos. En este sentido, para Heidegger la idea de lucha (Kampf) apunta no a la guerra violenta sino al estar-frente-al-otro (Aus-einandersetzung) que abre la posibilidad del diálogo (Gespräch) y la develación por medio del estar-expuesto para el mutuo reconocimiento. 2) La segunda forma de entender apunta, por el contrario, a la idea que apoya del Nacionalsocialismo que sí indica combatir y defender las convicciones hasta sus últimas consecuencias.

Tal como mencionamos en el segundo apartado de este escrito, con esta forma de la solicitud los hombres se vinculan desde el compromiso, la lealtad y la fidelidad. Por el compañerismo los hombres tienen una pertenencia común a un proyecto con un mismo objetivo y camino. Así para Heidegger el compañerismo es la forma fundamental de la comunidad que se genera en los que son conducidos. Para que se despliegue la comunidad debe darse el compañerismo pues sólo puede hablarse de una comunidad cuando, de hecho, surge entre los hombres un sentido de pertenencia e identidad, y éste se consolida a partir de un proyecto compartido. Así el compañerismo es un mecanismo natural que genera nuevas necesidades en la comunidad, puesto que se patentizan, 
dentro del juego de relaciones, otro tipo de exigencias debido a que los vínculos son más profundos e íntimos entre sus integrantes. De este modo, las demandas van despertando en el pueblo la necesidad de un guía (Führer), ${ }^{20}$ el que lleve nuevamente al pueblo a su propia definición y a una nueva voluntad de existencia.

Heidegger entiende que el profesor debe estar cerca del peligro, enfrentarse a él y soportarlo para hacer surgir su indigencia y de este modo, engendrar la pregunta esencial. El guía (Führer) no tiene en sí ansias de poder y dominio pues es la esencia misma, su vocación, la que lo impulsa a llevar a cabo su destino. El problema se halla en que pocos tienen el valor de reconocer los indicios del guía y muchos, por seguir al común, pierden de vista el objetivo emprendido. De ahí que sólo unos pocos -aquellos que en otros escritos del autor como Beiträge zur Philosophie y Besinnung serán los futuros (die Zukünftige)podrán oponerse al rebaño, el camino aglutinante del "uno". Con todo, Heidegger propone que los alumnos deben vincularse y servir a Alemania. Para esto el filósofo distingue tres tipos de vinculación del pueblo en busca del destino desde el camino espiritual. Estos son: 1) el servicio del trabajo para afianzar la comunidad, participando, compartiendo y co-ejerciendo en el estado, 2) el servicio de las armas por el honor y el destino de la nación y 3) el servicio del saber, esta es la misión espiritual del pueblo que expone la problemática de su existencia humana. La conjunción de estas tres instancias prácticas lleva a la comunidad a la puesta en obra de su misión. El pueblo afianza su identidad y pertenencia cultural gracias al equilibrio fáctico de estos servicios, ya que se encuentran dentro del mismo espacio de emergencia. Aunque vistos los servicios desde el plano ontológico, puede decirse que en el ámbito del saber todo se subsume. En este pasaje se hace evidente el lazo entre la educación y el trabajo, claro rasgo de la militancia del partido en vigencia que Heidegger rescataba como característica positiva de la doctrina.

\section{El discurso y la obra. Una distinción en el pensar del filósofo}

Es apresurado condenar o alabar el pensamiento de Heidegger. Para juzgar su obra o su participación pública se necesita un análisis cuidadoso y detallado de cada situación dentro del pertinente contexto significativo, puesto que hay un gran desnivel -como

20 Sobre la definición del guía dice Heidegger: "Sólo quien oye de verdad y puede obedecer, puede también conducir (führen). Conductor, guía, (Führer) no es aquél, que está puesto antes que los otros (vor-gesetzt), aquel que con los demás puede oír de una manera más incondicional y obedecer de un modo más resuelto la ley. Conductor es aquel, que hace más que los otros, porque es capaz de soportar más, aventurar más y sacrificar más." HEIDEGGER, "Die deutsche Universität" en Reden und andere Zeugnisse. Eines Lenbensweges, GA 16, Frankfurt am Main: Vittorio Klostermann, 2000, p. 300. 
afirman los comentaristas Ferry y Renaut- entre el Heidegger filósofo y el ciudadano. Si no diferenciamos su pensamiento de su compromiso político se produce una simplificación que malogra los contenidos. Inclusive hay que hacer una salvedad, a saber, que la posición del autor varía en el tiempo. ${ }^{21}$

Las ideas contenidas en sus escritos filosóficos, inclusive en Sein und Zeit, no conforman semánticamente un exclusivo conjunto de nociones de matiz político. Por lo tanto, extrapolar los elementos desarrollados en estas obras para darles una interpretación a través de parámetros que no pertenecen al ámbito propio de su génesis, genera la ulterior deformación de su sentido. Por ende, debe admitirse que es preciso realizar una revisión neutral de los escritos puesto que sólo es posible una lectura fiel fuera de las estrategias de tergiversación intencional del sentido. De allí que no sea lo mismo referirse al pensar de Heidegger en su producción filosófica que prestar atención a sus discursos pronunciados en eventos públicos y político-académicos, porque estos últimos sí poseen en germen una impronta de las tensiones institucionales, el clima político y las preferencias partidarias del autor alemán.

Los pensadores franceses de la comunidad tienen muy clara esta cuestión, ellos indican con rigurosa precisión los aportes de Heidegger. Por ejemplo el uso y reformulación de las nociones heideggerianas se realiza con cuidado y con un análisis crítico particular que les permite incorporarlas a su discurso dándoles un tono propio. Por otro lado, ellos sólo toman del pensamiento del filósofo alemán aquello que les sirve para su propuesta y no intentan tergiversar el sentido de su obra. A diferencia de los pensadores de la comunidad, otros estudiosos y comentaristas de la obra de Heidegger exponen sus interpretaciones de forma tal que fuerzan el sentido de los conceptos con tal de discutir la presencia del nazismo en ellos. No obstante, la perspectiva francesa logra detenerse en análisis políticos y dirigirlos con total independencia y voz propia hacia su exposición.

Ahora bien, una vez que concluimos la descripción del sentido de la comunidad en Heidegger dentro del contexto de los discursos del Rectorado y atendiendo a la situación particular en la que éstos se desarrollan, podemos ver que tal comprensión de la comunidad refiere a la idea de la inmunidad presentada por los pensadores de la comunidad, más que a la propuesta de esta línea. La comunidad en Heidegger está encaminada a una meta específica que es la de reorganizar o acomunar al sector intelectual y a la Alemania de su época a partir de ciertos valores. Como pudimos ver es central para el filósofo accionar

21 Su postura confiada en el proyecto del Nacionalsocialismo y su ímpetu de unirse al llamado del Führer, se descontinúa en sus obras de 1936/38 Beiträge zur Philosophie y Besinnung posteriores al Rectorado, culminando en una visión crítica de las elecciones y medios de la puesta en escena del partido y de Hitler. 
frente a la situación particular y destacar entre los compañeros algo a preservar. Para la perspectiva francesa más que una acción, esto es una reacción de un sector frente a la desintegración. Pareciera que lo que Heidegger quiere frenar es la visión moderna de la ramificación científica y los valores individualistas, pero de acuerdo a las lecturas de los franceses acerca de las nociones de Heidegger vemos que la modernidad sigue presente en sus ideas.

No se puede negar que cada pensar está ligado a su época y de allí se sigue también que se pueda dilucidar cierta inquietud predominante entre los puntos o problemáticas trabajadas por Heidegger. Es evidente la fuerte presencia de algunas ideas a lo largo de su meditación, ${ }^{22}$ de allí que en adelante se considere su cercanía a ciertas temáticas políticas. Más allá de esto, la línea francesa logra distinguir a qué se refiere Heidegger en sus obras, sea a su desarrollo de la analítica existencial o sus discursos del rectorado. Entendemos que el pensamiento de los franceses emerge en una encrucijada entre la ontología y la política, y que ellos estudian aspectos de la comunidad desde una mirada ontológica. Pero fuera de ello lo que en este momento queremos aclarar es que hay que tener un particular cuidado con la lectura de la obra del filósofo. Heidegger no elaboró explícitamente una política -incluso se negó a hablar de una dimensión política en sus escritos- así que no se puede hacer decir al autor aquello que explícitamente no dijo él mismo.

Respecto a sus preferencias en torno a lo político, Heidegger indica que su posición difiere de las visiones del partido Nacionalsocialista en algunos puntos, como por ejemplo, en la cosmovisión y las doctrinas biológicas, raciales y bélicas. ${ }^{23}$ En consecuencia, no es apropiado identificarlo directamente con el nazismo y con las actividades del partido en vigencia. Primero porque el autor afirma reiteradas veces que su afiliación al partido fue un requisito a efectuar burocráticamente por su puesto en el rectorado de la Universidad de Friburgo, puesto a que al cabo de un año dejó por diferencias sustanciales, y segundo porque él argumenta que acordó en dicho período no participar de ninguna de las

22 Félix Duque dice en "La guarda del espíritu. Acerca del nacional-socialismo de Heidegger": “... si tal evolución conlleva una auténtica autocrítica; es decir, si a través de textos filosóficos, y no por confesiones a autoridades académicas o a medios de comunicación, ha renegado Heidegger de verdad de su pasado. Salvo en cuestiones personales creo que él nunca se excusó de su pensar (...) mientras que en lo político pasó de un activismo antidemocrático y voluntarista visceral a una actitud escéptica respecto a la función de la democracia en el mundo actual." DUQUE, F., "La guarda del espíritu. Acerca del 'nacional-socialismo' de Heidegger" en AAvv, Heidegger: La voz de tiempos sombríos, Barcelona: Ediciones del Serbal, 1991, pp. 86-87.

23 Pese a que los comentaristas Ferry y Renaut no tienen una visión positiva de Heidegger, destacan que éste se opuso sin duda al antisemitismo, el exterminio y al biologismo de Rosenberg. 
tareas políticas en cuestión. ${ }^{24}$ Heidegger cuenta que Wacker, el ministro de cultura de Baden, Ilega a acusarlo de Privatnationalsozialismus. Esto nos lleva a comprender cómo su pensamiento se funda en la propia expresión de un ideal que se desenvuelve en un conjunto de apreciaciones que, de hecho, no coincidían con los medios y actitudes del tercer Reich.

Igualmente hay que destacar que toda idea de trabajo y militancia en esta época está directamente relacionada con el discurso y la persuasión de Hitler. Aunque no se podrá corroborar si más allá de la influencia romántica en Heidegger, que como sabemos contiene gran parte de estos elementos discursivos, existió en el corto período del Rectorado de Friburgo una obligación de divulgar estos objetivos o un interés particular del filósofo por reforzar esta misión en los estudiantes, tal como lo hace bajo la idea del saber para la universidad.

Como dijimos, creemos que hay que dirigir la mirada hacia los discursos del Rectorado ya que en estos hay fuertes alusiones ideológicas. Esto se debe a que más allá de la ausencia de un antisemitismo -hasta los actualmente conocidos y discutidos Schwarze Hefte- están presentes ideas sombrías como la figura de un guía, la lucha y la purificación del sector intelectual. Si seguimos la lectura francesa veremos que las ideas de comunidad, compañerismo y fidelidad tienen toda la connotación negativa de la "comunidad para la muerte" y de la figura del endiosamiento del guía. En este marco, el peso de la identidad y pertenencia convierten a la comunidad en totalitarismo y al pensar en filosofía de la inmanencia. Además, nos encontramos frente a un pensador que no analiza la crudeza del Holocausto y que encamina su reflexión de los ' 30 hacia un pensar radical sobre lo originario. Este pensar plantea una experiencia del acontecer con ciertos matices axiológicos que derivan en una noción de comunidad fundada en los ideales de la identidad, la patria, la tierra, la pertenencia y la apropiación. Por otro lado, Heidegger procede en el ámbito público con un discurso que sólo destaca los valores del Nacionalismo que a él le interesa reforzar para reorganizar a la universidad y al saber de acuerdo a los compromisos frente a un guía espiritual, un destino y la custodia de una herencia.

El pensar de Heidegger intenta comprender la experiencia del hombre en el momento histórico en que se encuentra y apunta a descubrir el temple de la sociedad, que según sus evaluaciones aún no reconoce su esencia. Siguiendo esta óptica, podríamos inferir

24 Estas dos cuestiones, mencionadas por Heidegger en la entrevista con Der Spiegel, hay que ponerlas entre paréntesis, porque las investigaciones de Farías pronuncian que el filósofo estaba afiliado y pagaba sus cuotas del Nationalsocialistische Deutsche Arbeiter Partei hasta 1945 y que su actividad política fue intensa después del Rectorado. 
que Heidegger no cumple con su planteo de atender esta situación que tanto demanda la intervención y la decisión por un cambio radical. Por el contrario, en cierto modo -tal como otros pensadores alemanes contemporáneos- Heidegger inscribe su discurso, en términos generales, en la decadencia del mundo de la técnica, Europa y la filosofía occidental. Con todo, podemos afirmar que el filósofo evita el compromiso de una reflexión abocada a desentrañar los efectos nefastos de este pensar y se refugia en la justificación de que él no hace filosofía política, del mismo modo que no elabora una ética o una estética. Aunque no puede negarse que su reflexión tiene implicancias políticas, más allá de que pretenda o no tenerlas.

En el texto de Ferry y Renaut hay una pregunta que consideramos resume todas las críticas posibles a Heidegger, que dice así:

¿Qué aspecto del nazismo pudo seducir a Heidegger, motivar un compromiso que sobrevino seis años después de Ser y Tiempo y llevarlo a asumir hasta la década de 1950 la idea de que, a pesar de las culpas y los extravíos nazis, hubo de todos modos 'una grandeza y una verdad interna del nacionalsocialismo'?25

Esta pregunta resume la indigencia del pensar del autor que aqueja a aquellos seguidores que le reprochan el no haberse retractado.

\section{Una última reflexión}

Una vez desarrollados, a grandes rasgos, los elementos que distinguen al pensamiento francés, podemos ver que la comunidad en Heidegger se encuentra primordialmente en las antípodas de esta visión. Tal como se describió en el apartado de la articulación de las ideas del filósofo alemán en el período del Rectorado, no hay oposición más notoria que su subscripción de la comunidad al ámbito de la identidad y la pertenencia.

Heidegger se espanta con la desintegración de la ciencia y reclama un fundamento único en el saber. El filósofo diagnostica en su período una decadencia y deterioro de la esencia, y proclama volver a la integración. Ya Bataille nos muestra en La conjuración sagrada que los movimientos revolucionarios, como lo fue el Nacionalsocialista, buscan recomponer el estado por su aversión a la descomposición y, de este modo, paralizan el 
movimiento de la existencia que exige una desintegración constante. ${ }^{26}$ También Nancy marca en La comunidad enfrentada cómo

la comunidad exige soberanía e intimidad, presencia a sí sin falla. (...) Se desea el 'espíritu' de un 'pueblo' o el 'alma' de una asamblea de 'fieles', se desea la 'identidad' de un 'sujeto' o su 'propiedad'. ${ }^{27}$

Por otro lado, tanto Heidegger como los franceses están en contra de la idea de un humanismo, pero de forma muy distinta. Heidegger no apoya la idea universal porque está en contra de toda forma vacía de unidad, él se encuentra del lado del comunitarismo o de la idea de comunidades con su propia historia. En cambio, los franceses están en contra de "toda idea de comunidad", sea particular o universal, porque hasta esta última se desgarra.

De todas maneras, los franceses retoman algunos conceptos del autor y descubren en ellos un pensar sobre el origen que merece considerarse, a pesar de las distancias entre las visiones. La comunidad en Heidegger representa el polo opuesto a la comunidad de los franceses, pero a la vez permanece unida a ella. La perspectiva de la línea francesa destaca que esta forma de comunidad en Heidegger apunta a lo que algunos de ellos, siguiendo a Esposito, entienden como inmunidad. Es decir, que por ejemplo la comunidad heideggeriana es la deriva de la versión original de la comunidad. El problema de la comunidad se presenta en estos pensadores a partir de la dificultad de definirla, justamente porque ésta se realiza en la negación. Por ende, cuando se intenta hablar de ella se la determina de forma tal que se niega su esencia. Sin embargo, ya Derrida nos dice en su texto $L a$ hospitalidad ${ }^{28}$ que es imposible la realización de la hospitalidad incondicionada, sólo se puede dar una tendencia al perfeccionamiento de la hospitalidad condicionada. Esta idea nos sirve para destacar que existen formas de exponer a la comunidad por medio de su deriva inmunitaria y -como dice Esposito- éstas no deben anularse porque en su interior reside parte de la comunidad. En todo caso, por ahora sólo nos queda pensar en una comunidad como un ideal regulativo, para contrarrestar las fuerzas que condicionan y organizan a los hombres. Nancy habla de un movimiento pendular que lo conducía desde y hacia la obra de Blanchot, hacia el problema de lo inconfesable, desde una pregunta por la comunidad y hacia un pensamiento destinado a emanciparse de la pregunta. En esta oscilación intuye que "no dejaremos de ser guiados

26 Cfr. BATAILle, Georges, "Proposiciones" en La conjuración sagrada. Ensayos 1929-1939, Buenos Aires: A. Hidalgo, 2003, p. 182.

27 NANCY, La comunidad enfrentada cit., p. 12.

28 Véase DERRIDA, La hospitalidad, Buenos Aires: Ediciones de la Flor, 2008. 
por ese movimiento", al menos mientras una comunidad de naturaleza inédita no haya encontrado lugar entre nosotros. ${ }^{29}$

Ahora, acerca del puesto del hombre en la comunidad y del temple de ánimo que lo dispone, Heidegger y los franceses llegan al mismo dilema, aunque por distintos caminos. Por ejemplo, Nancy se cuestiona:

¿Cómo volvernos capaces de mirar a la cara nuestro vacío y nuestro enfrentamiento, no para sumergirse en ellos, sino para hallar, pese a todo, la fuerza de enfrentarnos, primero con conocimiento de causa, luego de manera tal que podamos realmente encararnos ${ }^{30}$

A partir de este planteo -que en este caso corresponde a los franceses, pero bien podría ser de Heidegger- enfrentamos los dos polos en el entre de la problemática de la comunidad, ya que esta pregunta ilustra la intención de ambas visiones. Heidegger desafía lo que llama "la indigencia del pensar" para su reconocimiento, de modo tal que el hombre asuma el temple en ese momento y retorne la atención a sí para un cambio respecto de lo común. Los franceses se inclinan a la presencia del abismo, para descubrir la nada que somos y desligarnos de toda falsa comunidad. Si retomamos el primer epígrafe de este trabajo, podremos constatar la tensión y oscilación propia del término "comunidad", que nos conduce a los dos polos para enfrentarlos y discurrir por estas dos alternativas, miradas que reflejan la problemática.

\section{Bibliografía}

BATAille, G.: "Proposiciones" en La conjuración sagrada. Ensayos 1929-1939, Buenos Aires: A. Hidalgo, 2003.

BLANCHOT, M.: La comunidad inconfesable, Madrid: Arena Libros, 1999.

CRAGNOLINI, M.: "Extrañas comunidades. Para una metafísica del exilio" en CRAGNOLINI, M. (comp.), Extrañas comunidades. La impronta nietzscheana en el debate contemporáneo, Buenos Aires: La cebra, 2009.

CRAGNOLINI, M.: "Temblores del pesar: Nietzsche, Blanchot, Derrida" en Pensamientos de los confines, $\mathrm{N}^{\circ} 12$, junio, 2002.

DERRIDA, J.: La hospitalidad, Buenos Aires: Ediciones de la Flor, 2008.

29 Cfr. BLANCHOT, La comunidad inconfesable cit., 1999, p. 34.

30 Esta pregunta la realiza Nancy en La comunidad enfrentada cit., p. 14. 
DUQUE, F.: “La guarda del espíritu. Acerca del ‘nacional-socialismo' de Heidegger” en AAVV, Heidegger: La voz de tiempos sombríos, Barcelona: Ediciones del Serbal, 1991.

ESPOSITO, R.: Communitas. Origen y destino de la comunidad, Buenos Aires: Amorrortu, 2003.

ESPOSITO, R.: Immunitas. Protección y negación de la vida, Buenos Aires: Amorrortu, 2005.

FERRY, L.; RenAUt, A.: Heidegger y los modernos, Buenos Aires: Paidos, 2001.

HEIDEGGER, M.: Reden und andere Zeugnisse. Eines Lenbensweges, GA 16, Frankfurt am Main: Vittorio Klostermann, 2000.

HEIDEGGER, M: Beiträge zur Philosophie. Vom Ereignis, GA 65, Frankfurt am Main: Vittorio Klostermann, 1994.

HEIDEGGER, M.: Besinnung, GA 66, Frankfurt am Main: Vittorio Klostermann, 1997.

HEIDEGGER, M.: Überlegungen II-VI (Schwarze Hefte 1931-1938), GA 94, Franckfurt am Main: Vittorio Klostermann, 2014.

HEIDEGGER, M.: Überlegungen VII-XI (Schwarze Hefte 1938-1939), GA 95, Franckfurt am Main: Vittorio Klostermann, 2014.

HEIDEGGER, M.: Überlegungen XII-XV (Schwarze Hefte 1939-1941), GA 96, Franckfurt am Main: Vittorio Klostermann, 2014.

HEIDEGGER, M.: Sein und Zeit, Tübingen, Max Niemeyer Verlag, 1960.

NANCY, J-L.: La comunidad desobrada, Madrid: Arena Libros, 2011.

NANCY, J-L.: La comunidad enfrentada, Buenos Aires: La cebra, 2007. 